\title{
Effect of PD-I inhibitor on exhaled nitric oxide and pulmonary function in non-small cell lung cancer patients with and without COPD
}

This article was published in the following Dove Press journal: International Journal of Chronic Obstructive Pulmonary Disease

Yuzo Suzuki,' Naoki Inui, ' Masato Karayama,' Shiro Imokawa, ${ }^{2}$ Takashi Yamada, ${ }^{3}$ Koushi Yokomura, ${ }^{4}$ Kazuhiro Asada, ${ }^{5}$ Hideki Kusagaya, ${ }^{6}$ Yusuke Kaida, ${ }^{7}$ Hiroyuki Matsuda, ${ }^{8}$ Naoki Koshimizu, ${ }^{9}$ Mikio Toyoshima, ${ }^{10}$ Masafumi Masuda,"

Hiroshi Hayakawa, ${ }^{2}$ Hironao Hozumi,

Kazuki Furuhashi,' Noriyuki Enomoto,'

Tomoyuki Fujisawa,'

Yutaro Nakamura,' Takafumi Suda'

'Second Division, Department of Internal Medicine, Hamamatsu University School of Medicine, Hamamatsu, Japan; ${ }^{2}$ Department of Respiratory Medicine, Iwata City Hospital, Iwata, Japan; ${ }^{3}$ Department of Respiratory Medicine, Shizuoka City Shizuoka Hospital, Shizuoka, Japan; ${ }^{4}$ Department of Respiratory Medicine, Seirei-Mikatahara Hospital, Hamamatsu, Japan; ${ }^{5}$ Department of Respiratory Medicine, Shizuoka General Hospital, Shizuoka, Japan; ${ }^{6}$ Department of Respiratory Medicine, Shizuoka Saiseikai Hospital, Shizuoka, Japan; ${ }^{7}$ Department of Respiratory Medicine, JA Shizuoka Kohseiren Enshu Hospital, Hamamatsu, Japan;

${ }^{8}$ Department of Respiratory Medicine,

Shizuoka Red Cross Hospital, Shizuoka, Japan;

${ }^{9}$ Department of Respiratory Medicine,

Fujieda City Hospital, Fujieda, Japan;

${ }^{10}$ Department of Respiratory Medicine, Hamamatsu Rosai Hospital, Hamamatsu, Japan; "'Department of Respiratory Medicine, Shizuoka City Shimizu Hospital, Shizuoka, Japan; ${ }^{12}$ Department of Respiratory Medicine, Tenryu Hospital, National Hospital Organization, Hamamatsu, Japan

Correspondence: Yuzo Suzuki Second Division, Department of Internal Medicine, Hamamatsu University School of Medicine, I-20-I Handayama Higashi-ku,

Hamamatsu, Shizuoka 43I-3192, Japan

Tel +8I 534352263

Fax +8I 534352354

Email yuzosuzu@hama-med.ac.jp
Background: Nivolumab, a programmed death 1 (PD-1) immune checkpoint inhibitor, has been shown to improve survival in non-small cell lung cancer (NSCLC). The possible involvement of PD-1 axis in the pathogenesis of inflammatory lung disease, such as chronic obstructive pulmonary disease (COPD) has also been reported. However, effects of PD-1 blockade on the respiratory system remain unknown.

Objectives: This prospective study aimed to investigate whether inhibition of the PD-1 axis altered lung inflammation and pulmonary function in NSCLC patients with and without COPD.

Method: This was a prospective multi-center study. Measurements of fractioned exhaled nitric oxide (FeNO) and pulmonary function were performed before and after 4 cycles of nivolumab therapy.

Results: A total of 137 patients with NSCLC were initially enrolled, and subsequently 95 patients (41 COPD and 54 non-COPD) receiving 4 cycles of nivolumab administration were included. After anti-PD-1 therapy, FeNO levels were significantly elevated together with increase in peripheral eosinophils. Interestingly, significant FeNO elevation was only found in COPD patients without increased peripheral eosinophils, but this was not the case in nonCOPD patients. Additionally, COPD patients exhibited significant increases in FVC and $\mathrm{FEV}_{1}$ but no changes in dyspnea scales, and acute exacerbation did not occur during the therapy.

Conclusion: Our observations suggest that anti-PD-1 therapy changed FeNO levels and pulmonary function in NSCLC patients. This therapy does not worsen COPD in terms of symptoms, pulmonary function, or acute exacerbation.

Keywords: immune checkpoint inhibitor, programmed death 1, PD-1, non-small cell lung cancer, NSCLC, chronic obstructive pulmonary disease, COPD

\section{Introduction}

Immune checkpoint inhibition targeting the programmed death-1 (PD-1) axis has been shown to improve survival in advanced non-small cell lung cancer (NSCLC) patients, ${ }^{1-6}$ and such immunotherapy is now a new paradigm for the treatment of NSCLC. The PD-1 pathway is one of various immune escape mechanisms. The PD-1 receptor expressed on activated T cells is engaged by ligands PD-L1 and PD-L2, which are expressed by tumor cells and infiltrating immune cells. ${ }^{7}$ Binding of PD-1 to its ligands on tumor cells strongly suppresses $\mathrm{T}$ cells through a negative feedback loop, leading to immune evasion and the development of cancer. ${ }^{8-10}$ Thus, blocking 
PD-1 signals restores anti-tumor immunity, resulting in prolonged survival in advanced NSCLC patients. ${ }^{1-6}$

As well as the desired anti-tumor effects achieved by activating the immune system, blocking the PD-1 axis has inflammatory side effects in a variety of organs, termed immune-related adverse events (ir-AE), such as thyroiditis, hypophysitis, colitis, autoimmune diabetes, and pneumonitis. ${ }^{11}$ The immunoregulatory roles of immune checkpoints are essential for immune system function even in healthy individuals, as they prevent excessive immune responses and maintain immune homeostasis. ${ }^{7,12}$ By virtue of its role in the immune system, the PD-1 axis is also involved in various inflammatory lung diseases including chronic obstructive pulmonary disease (COPD) and bronchial asthma. ${ }^{13-18}$

COPD is characterized by chronic inflammatory disease with obstructive pulmonary defects, and is most common comorbidity in patients with NSCLC. ${ }^{19}$ In COPD patients, overexpression of $\mathrm{PD}-1$ in $\mathrm{CD}^{+}, \mathrm{CD}^{+}$, and regulatory T cells, and impaired PD-L1 expression in macrophages and dendritic cells in the lung have been reported, ${ }^{15,17,20}$ suggesting that the PD-1-PD-L1 axis plays a role in its pathogenesis. Therefore, it has been hypothesized that further inhibition of the impaired PD-1-PD-L1 axis in COPD patients may increase airway inflammation and consequently promote disease progression. $^{21,22}$ Thus, understanding immune checkpoint biology in COPD is a new and potentially interesting field. ${ }^{21,22}$ Moreover, it is clinically important to clarify the effects of immune checkpoint inhibition on lung inflammation and physiology in COPD patients.

In practice, as non-invasive methods for assessing lung inflammation and pulmonary function, spirometry and fraction of exhaled nitric oxide (FeNO) are widely used. The levels of FeNO surrogate type 2 airway inflammation that regulated by IL-4 and IL-13 through STAT6 pathway, thus measurements of FeNO is used for diagnosis, prediction of inhaled corticosteroid (ICS) responsiveness, airway hyperresponsiveness and also monitoring type 2 airway inflammation in asthmatics. ${ }^{23}$ Importantly, type 2 airway inflammations were involved not only in asthmatics. Significant proportions of patients with asthma and/or COPD comprise features of both asthma and COPD that namely Asthma-COPD Overlap (ACO). ${ }^{24}$ The levels of FeNO in COPD patients were reported to range between healthy individuals and asthmatic, ${ }^{25}$ and were also shown to predict response to ICS. ${ }^{26-28}$ Additionally, T-helper2 (Th2) immunity is known to participate in tumor microenvironments. $^{29}$ Thus we hypothesized that anti-PD-1 therapy might alter FeNO levels and pulmonary function tests
(PFTs) via modifying type 2 airway inflammation and tumor microenvironments. Therefore, using these measurements, the current prospective study investigated whether anti-PD-1 therapy altered lung inflammation and pulmonary function in NSCLC patients with and without COPD.

\section{Methods}

\section{Ethical approval of the study protocol}

The present study was a multicenter prospective study conducted in accordance with the Declaration of Helsinki. The study protocol was approved by the ethics committee of each participating institutions; Hamamatsu University School of Medicine, Iwata City Hospital, Shizuoka City Shizuoka Hospital, Seirei-Mikatahara Hospital, Shizuoka General Hospital, Shizuoka Saiseikai Hospital, Enshu Hospital, Shizuoka Red Cross Hospital, Fujieda City Hospital, Hamamatsu Rosai Hospital, Shizuoka City Shimizu Hospital, and Tenryu Hospital, and was carried out in accordance with approved guideline. Written informed consent was obtained from all subjects in accordance with institutional guidelines. The study was registered in the University Hospital Medical Information Network in Japan (UMIN000021548). The study is registered in the University Hospital Medical Information Network in Japan (http://www.umin.ac.jp/ctr/index-j.htm). UMIN000021548.

\section{Patients}

Eligible patients had documented pathologically confirmed stage IIIB, stage IV, or unresectable stage IIIA NSCLC, or recurrent NSCLC after surgical resection, and had disease recurrence or progression during or after one prior systematic chemotherapy regimen. Patients were required to be aged more than 20 years and have an Eastern Cooperative Oncology Group performance status (ECOG) of 0,1 , or 2. Patients with treated, stable brain metastases were eligible. Additional eligibility criteria included adequate hematopoietic, hepatic, and renal function. Exclusion criteria were autoimmune disease, interstitial lung disease, systemic immunosuppression, concomitant chest radiotherapy, and prior treatment with checkpoint-targeting agents. Diagnoses and classifications of COPD were made in accordance with GOLD criteria, which is based on post-bronchodilator baseline lung function. ${ }^{30}$ Acute exacerbation of COPD (AE-COPD) was defined using the GOLD criteria, that is, a worsening of respiratory symptoms for two consecutive days or more. ${ }^{30}$ 


\section{Study design}

Patients received nivolumab at a dose of $3 \mathrm{mg} / \mathrm{kg}$ of body weight every 2 weeks. Before and after 4 cycles of nivolumab administration, FeNO measurement, PFTs, and blood analyses were performed.

\section{Evaluation of responses and toxicity}

Tumor responses were evaluated with reference to the computed tomography findings that had initially been used to define tumor extent. Responses were evaluated in accordance with the Response Evaluation Criteria in Solid Tumor version 1.1. Adverse events were graded using the National Cancer Institute Common Terminology Criteria for Adverse Events (version 4.0).

\section{FeNO measurement and PFTs}

The measurement of FeNO and PFTs were performed on the same day, and spirometry was performed after FeNO measurement in order to avoid any influence of forced breathing. Short-acting $\beta 2$ agonists were not withheld for at least $12 \mathrm{hrs}$ prior to these tests. All subjects also abstained from food and coffee for $2 \mathrm{hrs}$ prior to the tests, and from alcohol for $12 \mathrm{hrs}$ prior to the tests. FeNO was measured using the commercially available NIOX-VERO analyzer (Aerocrine, Solna, Sweden), in accordance with American Thoracic Society/European Respiratory Society recommendations. ${ }^{31}$ PFTs were performed in accordance with the Japanese Respiratory Society guidelines. ${ }^{32}$

\section{Modified medical research council questionnaire and COPD assessment test} The Modified Medical Research Council (mMRC) questionaire $^{33}$ and the COPD Assessment Test (CAT) ${ }^{34}$ (Japanese version, supplied by GlaxoSmithKline, Japan) were used to evaluate dyspnea in daily living. The mMRC questionnaire utilizes a 5-point scale, and patients are asked to rate dyspnea from 0 (absent) to 4 (dyspnea when dressing/undressing). The CAT consists of 8 items (cough, phlegm, chest tightness, breathlessness going up hills/stairs, activity limitations at home, confidence leaving home, sleep, and energy) that are used to assess and quantify COPD symptoms and their relative impacts on the patient. Each item is scored from $0-5$, resulting a total score ranging from 0 (best health status) to 40 (worst health status).

\section{PD-LI expression}

PD-L1 expression was assessed in formalin-fixed tumor samples derived from tumor-biopsy specimens at the time of NSCLC diagnosis in 69 patients, using the commercially available PD-1 IHC 22C 3 pharmDx assay kit (Dako, North America) on tumor-biopsy specimens at the time of NSCLC diagnosis. Samples were categorized as $0(<1 \%)$, $1+(\geq 1 \%$ and $<5 \%), 2+(\geq 5 \%$ and $<50 \%)$, or $3+(\geq 50 \%)$ based on a section that included at least 100 tumor cells that could be evaluated. ${ }^{1,4}$

\section{Statistical analysis}

Discrete variables are expressed as counts and percentages, and continuous variables are expressed as means \pm standard deviation, unless otherwise specified. The Wilcoxon matched-pairs signed rank test and Mann-Whitney test were used for matched and unmatched continuous variables, respectively. Statistical analyses were performed using GraphPad Prism Version 6 (GraphPad Software, San Diego, CA, USA) and SPSS Statistics (IBM Corporation, Armonk, NY, USA) software. All analyses were two-tailed, and $p<0.05$ was considered statistically significant.

\section{Results}

\section{Clinical characteristics}

A total of 137 patients were enrolled in the study, from April 2016 to March 2018. Of these, 42 discontinued treatment prior to completing 4 cycles of nivolumab, 27 exhibited disease progression, 14 experienced adverse events ( 7 pneumonitis, 2 colitis, 1 hypothyroidism, 1 increased creatinine, 1 rash acneiform, 1 pulmonary hemorrhage, 1 myositis), and 1 requested that the treatment be discontinued (Figure 1). The remaining 95 patients received nivolumab more than 4 cycles. Of these 95 NSCLC patients, FeNO was measured in 85 before and after 4 cycles of nivolumab treatment, and spirometry tests were performed in 90 before and after 4 cycles.

The clinical characteristics of the 95 NSCLC patients who received 4 cycles of nivolumab are shown in Table 1 . The median age at enrolment was 69 years (range 40-83 years), and 74 patients $(77.9 \%)$ were male. Sixty-nine $(72.6 \%)$ had stage IV NSCLC, and 15 (15.8\%) had stage IIIB. Sixty percent were diagnosed with adenocarcinoma, including 6 with epidermal growth factor receptor mutations. Of the 95 patients with NSCLC, 57 (60.0\%) had concomitant disease. COPD was the most common $(41,43.2 \%)$, followed by hypertension $(23,24.2 \%)$, and $3(3.2 \%)$ had bronchial asthma (two in COPD subgroup and one in non-COPD subgroup). Among 


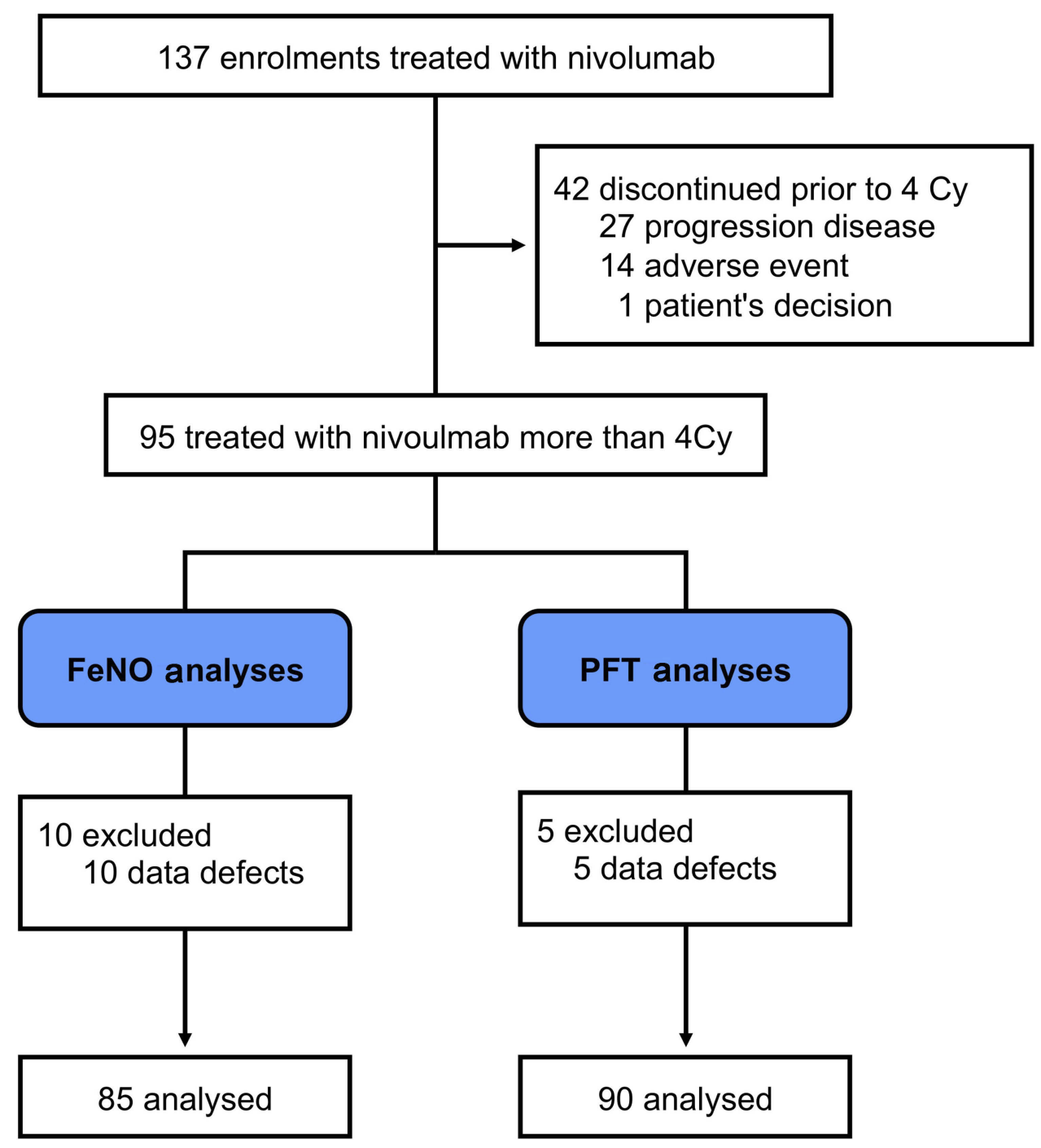

Figure I Study profile.

41 COPD patients, eight patients were treated with long-acting $\beta 2$ agonist (LABA) + long-acting muscarinic agonist (LAMA) combinations, and 4 with LAMA, whereas ICS, ICS+LABA combinations, ICS+LABA+LAMA were administered with one patients respectively. Among the 69 patients in which PD-L1 expression was assessed, in 23 (24.2\%) more than $5 \%$ of tumor cells exhibited PD-L1 expression, while no PD-L1 expression was observed in 37 patients (38.9\%). After 4 cycles of nivolumab treatment, 29 patients exhibited partial responses (PR), 30 exhibited stable disease (SD), and 36 exhibited progressive disease (PD).

Similar to typical COPD patients without lung cancer, NSCLC patients with COPD were significantly higher proportions of gender male $(p=0.0026)$ and smokers (former and current, $p=0.0027$ ). However, there were no significant differences in comorbidities, NSCLC stage, histology or PD-L1 expressions. The response rate $(\mathrm{PR}+\mathrm{SD})$ tended to be higher in NSCLC patients with COPD than those with non-COPD ( $75.0 \%$ vs $53.7 \%, p=0.0586)$.

\section{Effects of anti-PD-I therapy on FeNo, pulmonary function, dyspnea, and peripheral blood parameters}

After nivolumab therapy, FeNO levels were significantly increased (21.5 $\pm 14.7 \mathrm{ppb}$ to $25.2 \pm 16.8 \mathrm{ppb}, p=0.0242$ ) (Figure 2A). Nivolumab therapy changed FeNO levels by more than $10 \mathrm{ppb}$ in 23 patients $(24.2 \%)$ during the course of treatment (Figure 2B). In contrast, there were no significant differences in PFT results, mMRC questionnaire scores, or CAT scores before and after the nivolumab therapy. There were significant increases in eosinophil counts and percentages during the therapy (Table 2), but 
Table I Clinical characteristics of 95 patients with NSCLC

\begin{tabular}{|c|c|c|c|}
\hline & ALL cases $(n=95)$ & COPD $(n=4 I)$ & non-COPD $(n=54)$ \\
\hline Age, yr & $69(65-74 *)$ & $69\left(67-73^{*}\right)$ & $69(63-75 *)$ \\
\hline \multicolumn{4}{|l|}{ Sex } \\
\hline Male & 74 (77.9\%) & 38 (92.7\%) & $36(66.7 \%)$ \\
\hline Female & $21(22.1 \%)$ & $3(7.3 \%)$ & $18(33.3 \%)$ \\
\hline Observation & $56\left(5 \mathrm{I}-58^{*}\right)$ & $56\left(5 \mathrm{I}-58^{*}\right)$ & $56\left(5 \mathrm{I}-58^{*}\right)$ \\
\hline \multicolumn{4}{|l|}{ Smoking status } \\
\hline Never smoker & 17 (I7.9\%) & $0(\%)$ & 17 (3I.5\%) \\
\hline Former smoker & 69 (72.6\%) & $36(87.8 \%)$ & $33(61.1 \%)$ \\
\hline Current smoker & $9(9.5 \%)$ & $5(12.2 \%)$ & $4(7.4 \%)$ \\
\hline \multicolumn{4}{|l|}{ Comorbidity } \\
\hline COPD & $4 \mathrm{I}(43.2 \%)$ & - & - \\
\hline Hypertension & $23(24.2 \%)$ & $8(19.5 \%)$ & 15 (27.8\%) \\
\hline Cardiovascular disease & $9(9.5 \%)$ & $4(9.8)$ & $5(9.3 \%)$ \\
\hline Cerebrovascular disease & 7 (7.4\%) & $3(7.3 \%)$ & $4(7.4 \%)$ \\
\hline Digestive ulcer & $6(6.3 \%)$ & $2(4.9 \%)$ & $4(7.4 \%)$ \\
\hline Bronchial asthma & $3(3.2)$ & $2(4.9 \%)$ & I (I.9\%) \\
\hline GOLD stage, $1 / 1 / 1 / I I / / I V$ & \multicolumn{3}{|c|}{ II (26.8\%)/ 2 I (5I.2\%)/ 7 (I7.I\%)/ 2 (4.9\%) } \\
\hline \multicolumn{4}{|l|}{ Performance status at enrollment } \\
\hline 0 & $63(66.3 \%)$ & $26(63.4 \%)$ & $37(68.5 \%)$ \\
\hline 1 & $31(32.6 \%)$ & $15(36.6 \%)$ & $16(29.6 \%)$ \\
\hline 2 & $\mathrm{I}(\mathrm{I} . \mathrm{l} \%)$ & $0(0 \%)$ & $\mathrm{I}(1.9 \%)$ \\
\hline \multicolumn{4}{|l|}{ Stage } \\
\hline IIIA & $6(6.3 \%)$ & $4(9.8 \%)$ & $2(3.7 \%)$ \\
\hline IIIB & 15 (I5.8\%) & $9(22.0 \%)$ & $6(11.1 \%)$ \\
\hline IV & 69 (72.6\%) & $25(61.0 \%)$ & $44(81.5 \%)$ \\
\hline Recurrent & $5(5.3 \%)$ & $3(7.3 \%)$ & $2(3.7 \%)$ \\
\hline \multicolumn{4}{|l|}{ Histology } \\
\hline Adenocarcinoma & $57(60.0 \%)$ & $24(58.5 \%)$ & $33(61.1 \%)$ \\
\hline Squarmaous cell carcinoma & $36(37.9 \%)$ & $17(4 \mid .5 \%)$ & $19(35.2 \%)$ \\
\hline Other & $2(2.1 \%)$ & $0(0 \%)$ & $2(3.7 \%)$ \\
\hline \multicolumn{4}{|l|}{ PD-LI expression } \\
\hline$\geq 50 \%$ & $8(8.4 \%)$ & $3(7.3 \%)$ & $5(9.3 \%)$ \\
\hline$\geq 5 \%$ and $<50 \%$ & 15 (I5.8\%) & $6(14.6 \%)$ & 9 (16.7\%) \\
\hline$\geq 1 \%$ and $<5 \%$ & $9(9.5 \%)$ & $4(9.8 \%)$ & $5(9.3 \%)$ \\
\hline$<1 \%$ & 37 (38.9\%) & 14 (34.1\%) & $23(42.6 \%)$ \\
\hline Not examined & $26(27.4 \%)$ & $14(34.1 \%)$ & $12(22.2 \%)$ \\
\hline \multicolumn{4}{|l|}{ EGFR mutation status } \\
\hline Wild type & 73 (76.8\%) & $29(70.7 \%)$ & $44(81.5 \%)$ \\
\hline Positive mutation & $6(6.3 \%)$ & $2(4.9 \%)$ & $4(7.4 \%)$ \\
\hline Not examined & $16(16.8 \%)$ & $10(24.4 \%)$ & 6 (11.1\%) \\
\hline \multicolumn{4}{|l|}{ ALK fusion gene } \\
\hline Negative & 73 (76.8\%) & 29 (70.7\%) & 44 (8I.5\%) \\
\hline Positive & $0(0 \%)$ & $0(0 \%)$ & $0(0 \%)$ \\
\hline Not examined & $22(23.2 \%)$ & $12(29.3 \%)$ & $10(18.5 \%)$ \\
\hline
\end{tabular}

(Continued) 
Table I (Continued).

\begin{tabular}{|l|l|l|l|}
\hline & ALL cases (n=95) & COPD (n=4I) & non-COPD (n=54) \\
\hline Number of prior systematic regimens & & & \\
I & $43(45.3 \%)$ & $20(48.8 \%)$ & $23(42.6 \%)$ \\
2 & $25(26.3 \%)$ & $12(29.3 \%)$ & $13(24.1 \%)$ \\
3 & $10(10.5 \%)$ & $2(4.9 \%)$ & $8(14.8 \%)$ \\
$\geq 4$ & $17(17.9 \%)$ & $7(17.1 \%)$ & $10(18.5 \%)$ \\
\hline Efficacy of 4Cy treatment of nivolumab & & & $13(24.1 \%)$ \\
PR & $29(30.5 \%)$ & $16(39.0 \%)$ & $16(29.6 \%)$ \\
SD & $30(31.6 \%)$ & $14(34.1 \%)$ & $25(46.3 \%)$ \\
PD & $36(37.9 \%)$ & $11(26.8 \%)$ & \\
\hline
\end{tabular}

Note: *Median and interquartile range.

Abbreviations: COPD, chronic obstructive pulmonary disease; PD-LI, programmed death ligand I; EGFR, epidermal growth factor receptor; ALK, anaplastic lymphoma kinase; PR, partial response; SD, stable disease; PD, progressive disease.

there were no significant changes in other leukocytes, IgE, or CRP.

\section{Effects of anti-PD-I therapy in patients with COPD}

Involvement of the PD-1 axis in COPD has recently been reported, ${ }^{22,35}$ suggesting the possibility that blocking the PD1 axis may enhance lung inflammation in COPD patients, resulting in the deterioration of pulmonary physiology. However, this possibility has not yet been explored.
A

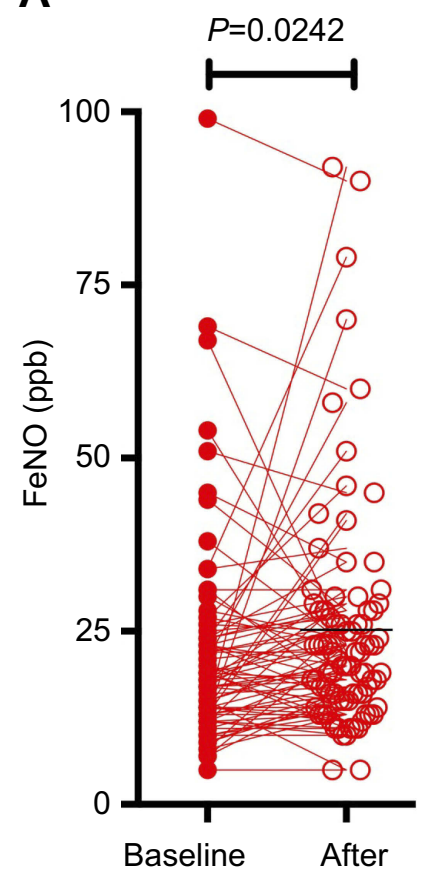

B

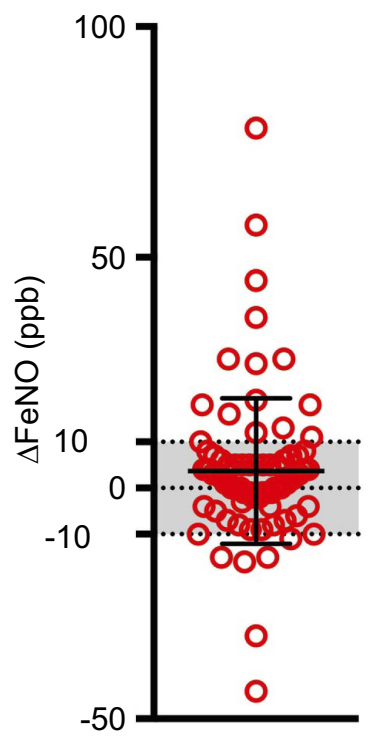

Figure 2 FeNO levels before and after four cycles of nivolumab treatment. (A) FeNO levels before (filled circle) and after (unfilled circle) 4 cycles of nivolumab treatment. (B) Differences in FeNO levels before and after 4 cycles of nivolumab.
Therefore, we selected 41 COPD patients from the cohort in the current study and evaluated changes in FeNO, spirometry parameters, and differential leukocyte counts in these patients, and compared the results to those derived from non-COPD patients. The characteristics of these COPD patients are shown in Table 1. Interestingly, although there was no significant change in FeNO in non-COPD patients after the therapy, COPD patients exhibited a significant increase in FeNO (Figure 3A and B). Nivolumab administration significantly increased FVC and $\mathrm{FEV}_{1}$ in COPD patients, but not in nonCOPD patients (Table 3). There were no significant changes in mMRC questionnaire scores or CAT scores after the therapy in COPD patients or non-COPD patients. In COPD patients there were no significant differences in differential leukocyte counts, whereas the numbers and percentages of eosinophils were significantly increased in non-COPD patients (Table 3 ). Importantly, no AE-COPD was observed during the treatment.

\section{Safety}

The major adverse events observed during the study are listed in Table 4. Seven patients experienced ir-AE, and hypothyroidism was most common. Myositis, type I diabetes mellitus, hyperthyroidism, and adrenal insufficiency were also observed. Four patients developed severe diarrhea, and 6 exhibited interstitial lung disease. There were 4 cases of lung infection, including two COPD patients with obstructive pneumonia due to disease progression.

\section{Discussion}

The present study prospectively investigated the effects of anti-PD-1 therapy on lung inflammation and pulmonary function in patients with NSCLC. In all subjects, after 4 cycles of nivolumab administration, FeNO levels were 
Table 2 Peripheral blood analyses before and after 4 cycles of nivolumab therapy in NSCLC patients with or without combined COPD

\begin{tabular}{|c|c|c|c|c|c|c|c|c|c|}
\hline & \multicolumn{3}{|c|}{ All cases $(n=95)$} & \multicolumn{3}{|c|}{ COPD cases $(n=4 I)$} & \multicolumn{3}{|c|}{ non-COPD cases $(n=54)$} \\
\hline & Baseline & After & $p$-value & Baseline & After & $p$-value & Baseline & After & $p$-value \\
\hline WBC $\left(/ \mathrm{mm}^{3}\right)$ & $6368(3745)$ & $6248(2 \mid 46)$ & 0.7207 & $5882(I 722)$ & $5990(1680)$ & 0.5528 & 678I (4757) & $6448(2445)$ & 0.9283 \\
\hline Neut $\left(/ \mathrm{mm}^{3}\right)$ & $4446(3324)$ & $4236(194 I)$ & 0.1199 & 3947 (I370) & $4003(1495)$ & 0.6168 & 4861 (4255) & $4416(2223)$ & 0.7188 \\
\hline Neut (\%) & $68.0(9.7)$ & $66.1(11.8)$ & 0.9342 & $66.6(10.5)$ & $65.5(10.9)$ & 0.4018 & $69.1(9.1)$ & $66.5(12.5)$ & 0.1749 \\
\hline Ly $\left(/ \mathrm{mm}^{3}\right)$ & $1208(555)$ & 1296 (659) & 0.1634 & $1237(520)$ & $1277(593)$ & 0.6628 & 1190 (589) & $|3| \mid(7||)$ & 0.2709 \\
\hline Ly (\%) & $20.3(8.1)$ & $22.1(10.5)$ & 0.2376 & $21.7(8.5)$ & $22.6(10.1)$ & 0.4701 & 19.1 (7.6) & $21.8(10.8)$ & 0.1901 \\
\hline Eo $\left(/ \mathrm{mm}^{3}\right)$ & $|7|(2 \mid 4)$ & $229(164)$ & 0.0010 & 208 (289) & $233(16 I)$ & 0.1116 & $142(129)$ & $226(168)$ & 0.0010 \\
\hline Eo $(\%)$ & $2.8(2.4)$ & $3.8(2.5)$ & 0.0005 & $3.2(2.9)$ & $3.9(2.6)$ & 0.1307 & $2.4(1.9)$ & $3.6(2.5)$ & 0.0018 \\
\hline $\mathrm{Ba}\left(/ \mathrm{mm}^{3}\right)$ & $39(46)$ & $38^{26}$ & 0.1590 & $35(28)$ & $34(24)$ & 0.9813 & $43(56)$ & $4 \mid(27)$ & 0.1836 \\
\hline $\mathrm{Ba}(\%)$ & $0.61(0.52)$ & $0.63(0.38)$ & 0.2826 & $0.60(0.43)$ & $0.58(0.37)$ & 0.6708 & $0.62(0.59)$ & $0.68(0.39)$ & 0.0429 \\
\hline Mo $\left(/ \mathrm{mm}^{3}\right)$ & $463(247)$ & $466(254)$ & 0.7007 & $434(200)$ & $444(183)$ & 0.5550 & $488(278)$ & $483(298)$ & 0.4805 \\
\hline Mo (\%) & $7.6(3.4)$ & $7.8(4.4)$ & 0.8240 & $7.6(3.2)$ & $7.5(2.3)$ & 0.9258 & $7.7(3.6)$ & $8.1(5.6)$ & 0.7431 \\
\hline $\lg E(I U / L)$ (n75) & I $79.8(253.0)$ & $187.9(236.8)$ & 0.1889 & I85.6 (205.6) & $217.4(224.5)$ & 0.1335 & I74.I (294.7) & I59.I (247.9) & 0.7007 \\
\hline CRP (mg/dl) & $1.67(3.04)$ & $1.30(1.59)$ & 0.1424 & $1.32(2.08)$ & $1.07(1.95)$ & 0.2182 & $1.95(3.63)$ & $1.48(3.00$ & 0.3856 \\
\hline $\operatorname{ESR}(\mathrm{mm})(\mathrm{n} 75)$ & $48.4(29.2)$ & $42.2(25.9)$ & 0.0365 & $45.6(30.4)$ & $38.3(23.1)$ & 0.1918 & $50.9(28.3)$ & $45.6(27.9)$ & 0.1182 \\
\hline $\operatorname{ESR}(\mathrm{mm})(\mathrm{n} 58)$ & $70.8(29.2)$ & 65.1 (27.2) & 0.2159 & $68.3(30.9)$ & $62.4(23.6)$ & 0.2343 & $73.1(28.1)$ & $67.4(30.2)$ & 0.5396 \\
\hline
\end{tabular}

A

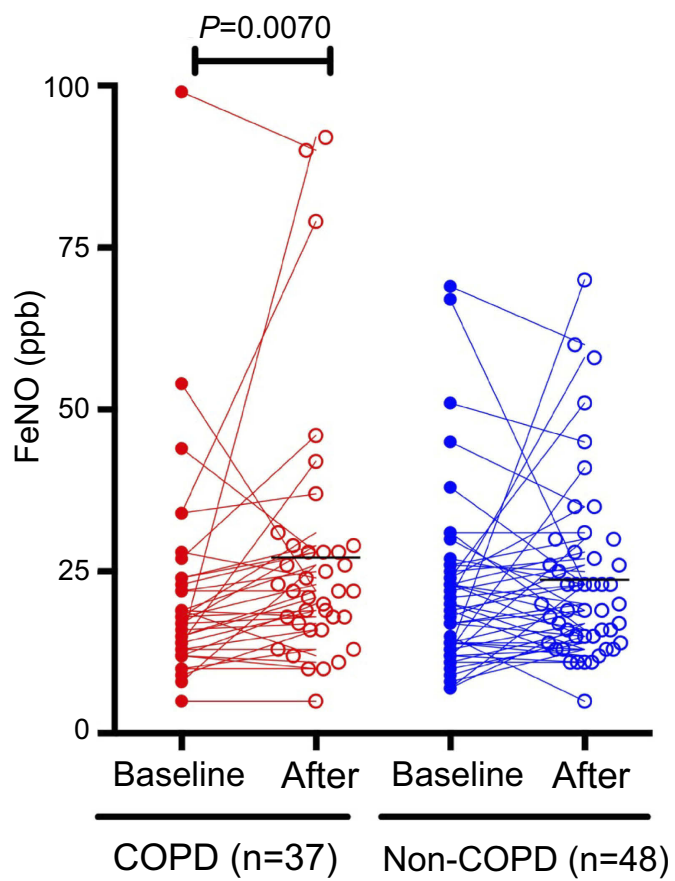

B

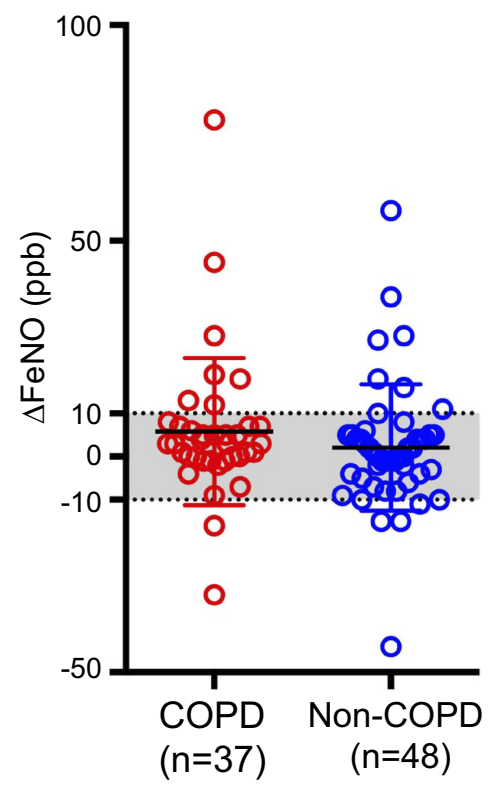

Figure 3 FeNO levels before and after four cycles of nivolumab treatment in patients with or without comorbid COPD. (A) FeNO levels before (filled circle) and after (unfilled circle) 4 cycles of nivolumab treatment in COPD and non-COPD patients. (B) Differences in FeNO levels before and after 4 cycles of nivolumab in COPD and nonCOPD patients.

significantly elevated with increased peripheral eosinophils. Interestingly, significant elevation of FeNO was only found in COPD patients without increased peripheral eosinophils, but not in non-COPD patients. In addition, COPD patients exhibited significant increases in FVC and
$\mathrm{FEV}_{1}$, and no AE-COPDs occurred during the therapy. The present study is the first to examine clinical implications of anti-PD-1 therapy in the respiratory system, and suggests the possibility that this therapy does not worsen COPD. 
Table 3 Pulmonary function tests before and after 4 cycles of nivolumab therapy in NSCLC patients with or without combined COPD

\begin{tabular}{|c|c|c|c|c|c|c|c|c|c|}
\hline & \multicolumn{3}{|c|}{ All cases $(n=90)$} & \multicolumn{3}{|c|}{ COPD cases $(n=40)$} & \multicolumn{3}{|c|}{ non-COPD cases $(n=50)$} \\
\hline & Baseline & After & $p$-value & Baseline & After & $p$-value & Baseline & After & $p$-value \\
\hline FVC (L) & $2.79(0.73)$ & $2.80(0.74)$ & 0.4446 & $2.89(0.84)$ & $2.98(0.80)$ & 0.0451 & $2.70(0.63)$ & $2.66(0.66)$ & 0.4665 \\
\hline FVC (\% pred) & $87.2(21.5)$ & $87.6(21.1)$ & 0.4639 & $86.8(22.7)$ & 89.1 (20.9) & 0.0635 & $87.6(20.7)$ & $86.4(21.4)$ & 0.4696 \\
\hline $\mathrm{FEV}_{1.0}(\mathrm{~L})$ & $1.95(0.54)$ & $1.96(0.54)$ & 0.4942 & $1.77(0.58)$ & $1.84(0.59)$ & 0.0350 & $2.09(0.46)$ & $2.05(0.48)$ & 0.2753 \\
\hline $\mathrm{FEV}_{1.0}(\%$ pred $)$ & $87.5(21.9)$ & $87.9(21.6)$ & 0.4665 & $69.4(21.1)$ & $71.2(19.9)$ & 0.0993 & $87.3(22.0)$ & $86.0(24.3)$ & 0.3097 \\
\hline $\mathrm{FEV}_{1.0} / \mathrm{FVC} \%$ & $70.2(11.5)$ & $70.8(12.2)$ & 0.6057 & $60.6(8.6)$ & $62.2(11.0)$ & 0.2004 & $77.9(6.9)$ & $77.7(8.1)$ & 0.6028 \\
\hline $\mathrm{SpO} 2$ (\%) & $96.9(1.7)$ & $96.6(1.7)$ & 0.2433 & $96.3(2.2)$ & $96.4(1.7)$ & 0.6215 & $97.2(1.2)$ & $96.7(1.6)$ & 0.0861 \\
\hline $\mathrm{mMRC}$ & $0.9(1.0)$ & $0.9(1.0)$ & 0.8602 & $1.2(\mathrm{I} . \mathrm{I})$ & $0.9(1.0)$ & 0.0918 & $0.7(0.9)$ & $0.8(I . I)$ & 0.1934 \\
\hline \multirow[t]{2}{*}{ CAT } & $8.3(6.6)$ & $8.2(7.1)$ & 0.7304 & $9.8(7.4)$ & $8.7(7.0)$ & 0.3005 & $7.2(5.5)$ & $7.8(7.2)$ & 0.5747 \\
\hline & \multicolumn{3}{|c|}{ All cases $(n=57)$} & \multicolumn{3}{|c|}{ COPD cases $(n=26)$} & \multicolumn{3}{|c|}{ non-COPD cases $(n=31)$} \\
\hline FRC (L) & $3.01(0.8 I)$ & $2.99(0.8 I)$ & 0.7317 & $3.27(0.85)$ & $3.30(0.94)$ & 0.9631 & $2.78(0.70)$ & $2.73(0.59)$ & 0.5595 \\
\hline FRC (\% pred) & $94.4(25.5)$ & $93.3(25.7)$ & 0.6040 & $91.0(24.6)$ & $90.5(24.8)$ & 0.7501 & $97.2(26.4)$ & $95.7(26.5)$ & 0.6461 \\
\hline $\mathrm{RV}(\mathrm{L})$ & $1.96(0.55)$ & $1.91(0.62)$ & 0.2403 & $2.12(0.54)$ & $2.14(0.73)$ & 0.8940 & $1.83(0.53)$ & $\mathrm{I} .72(0.4 \mathrm{I})$ & 0.1559 \\
\hline RV (\% pred) & II $6.6(29.6)$ & II $3.2(34.4)$ & 0.1219 & $124.8(29.1)$ & I25.4 (4I.4) & 0.6348 & $109.7(28.6)$ & $102.9(23.4)$ & 0.1156 \\
\hline TLC (L) & $4.87(1.15)$ & $4.83(1.13)$ & 0.7192 & $5.20(1.29)$ & $5.28(1.29)$ & 0.4265 & $4.60(0.98)$ & $4.45(0.81)$ & 0.2184 \\
\hline TLC (\% pred) & $97.6(20.2)$ & $96.5(20.1)$ & 0.4425 & $98.4(22.4)$ & $99.3(22.4)$ & 0.8564 & $96.9(18.4)$ & $94.1(18.0)$ & 0.1962 \\
\hline RV/TLC (\%) & $40.3(6.8)$ & $39.7(8.2)$ & $0.354 I$ & $4 I . I(6.2)$ & $40.5(8.2)$ & 0.4578 & $39.6(7.3)$ & 39.1 (8.4) & 0.5422 \\
\hline \%DLCO & $76.8(27.5)$ & $77.5(23.6)$ & 0.5046 & $69.8(26.7)$ & $72.4(24.7)$ & 0.2221 & $82.7(27.2)$ & $81.8(22.0)$ & 0.7942 \\
\hline
\end{tabular}

Abbreviations: FVC, forced vital capacity; $F E V_{1}$, forced expiratory volume in I.0 second; FRC, functional residual capacity; RV, residual volume; TLC, total lung capacity; DLCO, diffusing capacity of the lung for carbon monoxide; VA, alveolar volume; mMRC, modified Medical Research Council; CAT, COPD assessment test.

FeNO is widely considered to be a useful biomarker of airway inflammation in asthmatics. ${ }^{36,37}$ Following the upregulation of Th2 inflammatory cytokines IL-13 and IL-4, $\mathrm{NO}$ is excreted from the epithelium of the lower airway. Thus, FeNO is thought to reflect Th2 airway inflammation. In the present study, based on assessments in all subjects, FeNO levels were significantly elevated after the therapy. However, elevation was only evident in COPD patients, not in non-COPD patients. We hypothesized that Th2-dominant inflammation may be augmented in the lungs of COPD patients after anti-PD-1 therapy. However, there were no increases in peripheral eosinophil counts or serum IgE, suggesting that at least in terms of systemic immunity, anti-PD-1 therapy did not augment Th2-dominant immune responses in COPD patients. The fact that anti-PD-1 therapy only raised FeNO levels in COPD patients is intriguing, but the precise reason is unclear. Recent studies have shown that FeNO is also increased in non-Th2 inflammatory conditions such as hypersensitivity pneumonitis, ${ }^{38}$ pulmonary tuberculosis, ${ }^{39}$ and some viral infections, ${ }^{40}$ in which major sources of $\mathrm{NO}$ are thought to be macrophages and other immune competing cells expressing high levels of inducible nitric oxide synthase (iNOS). Thus, it may be that anti-PD-1 therapy enhances non-Th2 inflammation in the lungs of COPD patients, resulting in FeNO elevation. In the present study however, we did not assess lung inflammation using BAL or lung biopsy. Further studies incorporating such assessments will clarify these points.

Patients with COPD are susceptible to viral infections that causes disease exacerbations. ${ }^{41}$ In addition, the presence of COPD was associated with poor prognosis in patients with $\mathrm{NSCLC}^{42,43}$ Recent advances unveiled underlying mechanisms for these rationales, which is immune dysregulation in COPD. In the lungs of COPD, abundant numbers of exhausted PD-1 expressing CTL (cytotoxic $\mathrm{T}$ cells) together with immunosuppressive regulatory $\mathrm{T}$ cells and myeloid-derived suppressor cells were accumulated. These exhausted $\mathrm{T}$ cells with immune-regulatory cells are supposed to play a role in deteriorating COPD through cytotoxic immune dysfunction and aberrant immune regulation, such as impaired anti-viral and anti-tumor response. ${ }^{15,17,44,45}$ Interestingly, this study showed that patients with COPD tended to show higher response rate $(\mathrm{PR}+\mathrm{SD})$ than those with non-COPD patients $(75.0 \%$ vs $53.7 \%, p=0.0586)$. Aditionally, the present study indicated that anti-PD-1 therapy significantly increased $\mathrm{FVC}$ and $\mathrm{FEV}_{1}$ in COPD patients, but not in non-COPD patients. Possibly, anti-PD-1 therapy might ameliorate such immune dysfunction in COPD, although future studies using lung tissues or BAL will be needed to 
Table 4 Adverse events during the nivolumab therapy

\begin{tabular}{|l|l|l|l|}
\hline & $\begin{array}{l}\text { All cases } \\
\text { (n=95) }\end{array}$ & $\begin{array}{l}\text { COPD } \\
(\mathbf{n = 4} \text { I) }\end{array}$ & $\begin{array}{l}\text { non-COPD } \\
(\mathbf{n}=54)\end{array}$ \\
\hline Haematologic toxicity & & & \\
\hline Leucopenia & $2(0)^{*}$ & $\mathrm{I}(0)$ & $\mathrm{I}(0)$ \\
Neutropenia & $2(0)$ & - & $2(0)$ \\
Anemia & $\mathrm{I}(0)$ & $3(0)$ & $7(0)$ \\
Thrombocytopenia & $2(0)$ & - & $2(0)$ \\
\hline Non-haematologic toxicity & & & \\
ALT/AST increased & $4(2)$ & $\mathrm{I}(\mathrm{I})$ & $3(\mathrm{I})$ \\
Bilirubin increased & $\mathrm{I}(0)$ & - & $\mathrm{I}(0)$ \\
Creatinie increased & $4(0)$ & $\mathrm{I}(0)$ & $3(0)$ \\
Nausea/Appetite loss & $5(\mathrm{I})$ & - & $5(\mathrm{I})$ \\
Constipation & $2(0)$ & - & $2(0)$ \\
Diarrhea & $7(4)$ & $3(2)$ & $4(2)$ \\
Fatigue & $8(0)$ & $3(0)$ & $5(0)$ \\
Dysgeusia & $\mathrm{I}(0)$ & $\mathrm{I}(0)$ & - \\
Rash acneiform & $4(\mathrm{I})$ & $2(0)$ & $2(\mathrm{I})$ \\
Dry skin & $3(0)$ & $\mathrm{I}(0)$ & $2(0)$ \\
Pneumonitis & $6(0)$ & $3(0)$ & $3(0)$ \\
Lung infection & $4(3)$ & $2(2)$ & $2(\mathrm{I})$ \\
Haemoptysis & $\mathrm{I}(0)$ & - & $\mathrm{I}(0)$ \\
Thromboembolic events & $\mathrm{I}(0)$ & - & $\mathrm{I}(0)$ \\
Hyperglycemia & $\mathrm{I}(\mathrm{I})$ & - & $\mathrm{I}(\mathrm{I})$ \\
\hline Immune-rerated Adverse & & & \\
Events & & & - \\
Myositis & $\mathrm{I}(\mathrm{I})$ & - & $\mathrm{I}(\mathrm{I})$ \\
Type I Diabets Mellitus, & $\mathrm{I}(\mathrm{I})$ & - & $\mathrm{I}(\mathrm{I})$ \\
Hyperglycemia & $\mathrm{I}(\mathrm{I})$ & $\mathrm{I}(\mathrm{I})$ & - \\
Hyperthyroidism & $3(\mathrm{I})$ & $\mathrm{I}(0)$ & - \\
Adrenal insufficiency & $\mathrm{I}(0)$ & \\
\hline
\end{tabular}

Note: *Any (Grade $\geq$ III).

confirm this hypothesis. Increases in $\mathrm{FVC}$ and $\mathrm{FEV}_{1}$ were marginal less than $4 \%(0.09 \mathrm{~L}$ and $0.07 \mathrm{~L}$, respectively), and could be considered clinically unsubstantial, but the most important point is that anti-PD-1 therapy did not worsen pulmonary function in COPD patients. Dyspnea was also subjectively assessed via the mMRC questionnaire and the CAT, and there were no significant changes in either of the resulting scores. In addition, no AECOPDs occurred during the therapy. These observations suggest that anti-PD-1 therapy does not worsen COPD, despite increased FeNO, and may be safe in COPD patients.

To date, few studies have examined changes in peripheral differential leukocyte counts before and after immune checkpoint therapy. Interestingly, we observed a significant increase in peripheral eosinophil counts in all patients after anti-PD-1 therapy, and this increase was found only in non-COPD patients, but not in COPD patients. At baseline, eosinophil numbers were significantly higher in COPD patients than in non-COPD patients $\left(208 / \mathrm{mm}^{3}\right.$ vs $\left.142 / \mathrm{mm}^{3}\right)$, but after the therapy the numbers did not differ significantly $\left(233 / \mathrm{mm}^{3}\right.$ and $226 / \mathrm{mm}^{3}$, respectively). The mechanisms by which antiPD-1 therapy increases peripheral eosinophils in non-COPD patients are not clear. Future studies including larger numbers of patients will be required to confirm the findings of the current study, and elucidate the mechanisms involved.

The current study had several limitations. While changes in FeNO and pulmonary function after anti-PD-1 therapy were clearly evident, the detailed mechanisms underlying these observations remain to be characterized. Ideally, evaluations of BAL and/or lung species help to understand the mechanism, and these will form a part of future study. Secondly, the study did not include NSCLC patients who received less than 4 cycles of nivolumab administration. The main reasons for discontinuing the therapy were disease progression and/or severe adverse events. In such patients, the effects of anti-PD-1 therapy remain unclear. Thirdly, the number of COPD patients in the study was relatively small. Therefore, future studies including larger numbers of COPD patients will be needed to corroborate the results of the present study. Fourthly, while no AE-COPDs were observed during the therapy, the observation periods were relatively short (8-10 weeks). Future studies conducted over longer periods will provide more informative data in this regard. Lastly, the study focused solely on anti-PD-1 therapy. Thus, it is unknown whether our observations extend to other immune checkpoint inhibitors, such as anti-PD-L1 and CTLA-4 antibodies.

\section{Conclusion}

In conclusion, the present study prospectively explored the effects of anti-PD-1 therapy on the respiratory system by measuring FeNO and performing spirometry tests in NSCLC patients. Anti-PD-1 therapy did change FeNO levels and pulmonary function. Importantly, pulmonary function did not deteriorate in COPD patients during the therapy, there were no changes in dyspnea, and no AECOPDs occurred. The present study provides clinically important insights into immune checkpoint therapy, particularly with regard to COPD patients. Moreover, our observations warrant further studies investigating how immune checkpoint therapy may affect other inflammatory lung diseases such as bronchial asthma. 


\section{Acknowledgments}

We thank Editage for editing a draft of this manuscript.

This work was supported by a grant-in-aid for scientific research (16K19448 to YS) from the Japan Society for the Promotion of Science.

\section{Trial Registration}

The study is registered in the University Hospital Medical Information Network in Japan.

\section{Disclosure}

The authors report no conflicts of interest in this work.

\section{References}

1. Rittmeyer A, Barlesi F, Waterkamp D, et al. Atezolizumab versus docetaxel in patients with previously treated non-small-cell lung cancer (OAK): a phase 3, open-label, multicentre randomised controlled trial. Lancet. 2017;389:255-265. doi:10.1016/S0140-6736(16)32517-X

2. Reck M, Rodriguez-Abreu D, Robinson AG, et al. Pembrolizumab versus chemotherapy for PD-L1-positive non-small-cell lung cancer. $N$ Engl J Med. 2016;375:1823-1833. doi:10.1056/NEJMoa1606774

3. Herbst RS, Baas P, Kim D-W, et al. Pembrolizumab versus docetaxel for previously treated, PD-L1-positive, advanced non-small-cell lung cancer (KEYNOTE-010): a randomised controlled trial. Lancet. 2016;387:1540-1550. doi:10.1016/S0140-6736(15)01281-7

4. Fehrenbacher L, Spira A, Ballinger M, et al. Atezolizumab versus docetaxel for patients with previously treated non-small-cell lung cancer (POPLAR): a multicentre, open-label, phase 2 randomised controlled trial. Lancet. 2016;387:1837-1846. doi:10.1016/S0140-6736(16)00587-0

5. Brahmer J, Reckamp KL, Baas P, et al. Nivolumab versus docetaxel in advanced squamous-cell non-small-cell lung cancer. $N$ Engl J Med. 2015;373:123-135. doi:10.1056/NEJMoa1504627

6. Borghaei H, Paz-Ares L, Horn L, et al. Nivolumab versus docetaxel in advanced nonsquamous non-small-cell lung cancer. $N$ Engl J Med. 2015;373:1627-1639. doi:10.1056/NEJMoa1507643

7. Pardoll DM. The blockade of immune checkpoints in cancer immunotherapy. Nat Rev Cancer. 2012;12:252-264. doi:10.1038/nrc3239

8. Iwai Y, Ishida M, Tanaka Y, Okazaki T, Honjo T, Minato N. Involvement of PD-L1 on tumor cells in the escape from host immune system and tumor immunotherapy by PD-L1 blockade. Proc Natl Acad Sci U S A. 2002;99:12293-12297. doi:10.1073/ pnas.192461099

9. Dong H, Strome SE, Salomao DR, et al. Tumor-associated B7-H1 promotes T-cell apoptosis: a potential mechanism of immune evasion. Nat Med. 2002;8:793-800. doi:10.1038/nm730

10. Ribas A. Releasing the brakes on cancer immunotherapy. $N$ Engl J Med. 2015;373:1490-1492. doi:10.1056/NEJMp1510079

11. Postow MA, Sidlow R, Hellmann MD. Immune-related adverse events associated with immune checkpoint blockade. $N$ Engl J Med. 2018;378:158-168. doi:10.1056/NEJMra1703481

12. Francisco LM, Sage PT, Sharpe AH. The PD-1 pathway in tolerance and autoimmunity. Immunol Rev. 2010;236:219-242. doi:10.1111/ j.1600-065X.2010.00923.x

13. Akbari O, Stock P, Singh AK, et al. PD-L1 and PD-L2 modulate airway inflammation and iNKT-cell-dependent airway hyperreactivity in opposing directions. Mucosal Immunol. 2010;3:81-91. doi:10.1038/mi.2009.112
14. Bhat TA, Panzica L, Kalathil SG, Thanavala Y. Immune dysfunction in patients with chronic obstructive pulmonary disease. Ann Am Thorac Soc. 2015;12 Suppl 2:S169-S175.

15. Kalathil SG, Lugade AA, Pradhan V, et al. T-regulatory cells and programmed death $1+\mathrm{T}$ cells contribute to effector T-cell dysfunction in patients with chronic obstructive pulmonary disease. Am J Respir Crit Care Med. 2014;190:40-50. doi:10.1164/rccm.201312-2293OC

16. Keir ME, Butte MJ, Freeman GJ, Sharpe AH. PD-1 and its ligands in tolerance and immunity. Annu Rev Immunol. 2008;26:677-704. doi:10.1146/annurev.immunol.26.021607.090331

17. McKendry RT, Spalluto CM, Burke H, et al. Dysregulation of antiviral function of $\mathrm{CD} 8(+) \mathrm{T}$ cells in the chronic obstructive pulmonary disease lung. Role of the PD-1-PD-L1 axis. Am J Respir Crit Care Med. 2016;193:642-651. doi:10.1164/rccm.201504-0782OC

18. Singh AK, Stock P, Akbari O. Role of PD-L1 and PD-L2 in allergic diseases and asthma. Allergy. 2011;66:155-162. doi:10.1111/j.13989995.2010.02458.x

19. Young RP, Hopkins RJ, Christmas T, Black PN, Metcalf P, Gamble GD. COPD prevalence is increased in lung cancer, independent of age, sex and smoking history. Eur Respir J. 2009;34:380-386. doi:10.1183/ 09031936.00144208

20. Stoll P, Ulrich M, Bratke K, Garbe K, Virchow JC, Lommatzsch M. Imbalance of dendritic cell co-stimulation in COPD. Respir Res. 2015;16:19. doi:10.1186/s12931-015-0174-x

21. Wilkinson TMA. Immune checkpoints in chronic obstructive pulmonary disease. Eur Respir Rev. 2017;26:170045.

22. Stoll P, Virchow JC, Lommatzsch M. The PD-1-PD-L1 axis in chronic obstructive pulmonary disease. Am J Respir Crit Care Med. 2016;194:644. doi:10.1164/rccm.201604-0752LE

23. Dweik RA, Boggs PB, Erzurum SC, et al. An official ATS clinical practice guideline: interpretation of exhaled nitric oxide levels (FENO) for clinical applications. Am J Respir Crit Care Med. 2011;184:602-615. doi:10.1164/rccm.9120-11ST

24. Global Initiative for Asthma. Global strategy for asthma management and prevention [Updated 2019]. https:/ginasthma.org/wp-content/uploads/ 2019/06/GINA-2019-main-report-June-2019-wms.pdfhttps://ginasthma. org/wp-content/uploads/2019/06/GINA-2019-main-report-June-2019wms.pdf. Accessed July 15, 2019.

25. Ichinose M, Sugiura H, Yamagata S, Koarai A, Shirato K. Increase in reactive nitrogen species production in chronic obstructive pulmonary disease airways. Am J Respir Crit Care Med. 2000;162:701-706. doi:10.1164/ajrccm.162.2.9908132

26. Dummer JF, Epton MJ, Cowan JO, et al. Predicting corticosteroid response in chronic obstructive pulmonary disease using exhaled nitric oxide. Am J Respir Crit Care Med. 2009;180:846-852. doi:10.1164/rccm.200905-0685OC

27. Lehtimaki L, Kankaanranta H, Saarelainen S, et al. Bronchial nitric oxide is related to symptom relief during fluticasone treatment in COPD. Eur Respir J. 2010;35:72-78. doi:10.1183/09031936.00177508

28. Smith AD, Cowan JO, Brassett KP, et al. Exhaled nitric oxide: a predictor of steroid response. Am J Respir Crit Care Med. 2005;172:453-459. doi:10.1164/rccm.200411-14980C

29. Disis ML. Immune regulation of cancer. J Clin Oncol. 2010;28:45314538. doi:10.1200/JCO.2009.27.2146

30. Vogelmeier CF, Criner GJ, Martinez FJ, et al. Global strategy for the diagnosis, management, and prevention of chronic obstructive lung disease 2017 report. GOLD executive summary. Am J Respir Crit Care Med. 2017;195:557-582. doi:10.1164/rccm.201701-0218PP

31. American Thoracic S, European Respiratory S. ATS/ERS recommendations for standardized procedures for the online and offline measurement of exhaled lower respiratory nitric oxide and nasal nitric oxide, 2005. Am J Respir Crit Care Med. 2005;171:912-930. doi:10.1164/rccm.200406-710ST 
32. Clinical pulmonary functions committee of the Japanese Respiratory Society. Guideline for the Respiratory Function Tests-spirometry, Flow-volume Curve, Diffusing Capacity of the Lung [written in Japanese; Authors' Translation]. Tokyo: Medical Review Co.; 2001.

33. Bestall JC, Paul EA, Garrod R, Garnham R, Jones PW, Wedzicha JA. Usefulness of the Medical Research Council (MRC) dyspnoea scale as a measure of disability in patients with chronic obstructive pulmonary disease. Thorax. 1999;54:581-586. doi:10.1136/thx.54.7.581

34. Jones PW, Harding G, Berry P, Wiklund I, Chen WH, Kline Leidy N. Development and first validation of the COPD assessment test. Eur Respir J. 2009;34:648-654. doi:10.1183/09031936.00102509

35. Staples KJ, Wilkinson TM. Reply: the PD-1-PD-L1 axis in chronic obstructive pulmonary disease. Am J Respir Crit Care Med. 2016;194:644-645. doi:10.1164/rccm.201604-0863LE

36. Smith AD, Cowan JO, Brassett KP, Herbison GP, Taylor DR. Use of exhaled nitric oxide measurements to guide treatment in chronic asthma. N Engl J Med. 2005;352:2163-2173. doi:10.1056/NEJMoa043596

37. Kharitonov SA, Yates DH, Barnes PJ. Inhaled glucocorticoids decrease nitric oxide in exhaled air of asthmatic patients. Am J Respir Crit Care Med. 1996;153:454 457. doi:10.1164/ajrccm.153.1.8542158

38. Guilleminault L, Saint-Hilaire A, Favelle O, et al. Can exhaled nitric oxide differentiate causes of pulmonary fibrosis? Respir Med. 2013;107:1789-1796. doi:10.1016/j.rmed.2013.07.007

39. Wang $\mathrm{CH}$, Liu CY, Lin HC, Yu CT, Chung KF, Kuo HP. Increased exhaled nitric oxide in active pulmonary tuberculosis due to inducible NO synthase upregulation in alveolar macrophages. Eur Respir J. 1998;11:809-815.
40. Konstantinou GN, Xepapadaki P, Manousakis E, et al. Assessment of airflow limitation, airway inflammation, and symptoms during virusinduced wheezing episodes in 4- to 6-year-old children. J Allergy Clin Immunol. 2013;131:87-93.e81-85. doi:10.1016/j.jaci.2012.10.033

41. Global strategy for the diagnosis, management, and prevention of COPD. 2019. https://goldcopd.org/wp-content/uploads/2018/11/GOLD-2019-v1. 7-FINAL-14Nov2018-WMS.pdf. Accessed July 15, 2019.

42. Turner MC, Chen Y, Krewski D, Calle EE, Thun MJ. Chronic obstructive pulmonary disease is associated with lung cancer mortality in a prospective study of never smokers. Am J Respir Crit Care Med. 2007;176:285-290. doi:10.1164/rccm.200612-1792OC

43. Zhai R, Yu X, Shafer A, Wain JC, Christiani DC. The impact of coexisting COPD on survival of patients with early-stage non-small cell lung cancer undergoing surgical resection. Chest. 2014;145:346353. doi:10.1378/chest.13-1176

44. Biton J, Ouakrim H, Dechartres A, et al. Impaired tumor-infiltrating $\mathrm{T}$ cells in patients with chronic obstructive pulmonary disease impact lung cancer response to PD-1 blockade. Am J Respir Crit Care Med. 2018;198:928-940. doi:10.1164/rccm.201706-1110OC

45. Mark NM, Kargl J, Busch SE, et al. Chronic obstructive pulmonary disease alters immune cell composition and immune checkpoint inhibitor efficacy in non-small cell lung cancer. Am J Respir Crit Care Med. 2018;197:325-336. doi:10.1164/rccm.201704-0795OC

\section{Publish your work in this journal}

The International Journal of COPD is an international, peer-reviewed journal of therapeutics and pharmacology focusing on concise rapid reporting of clinical studies and reviews in COPD. Special focus is given to the pathophysiological processes underlying the disease, intervention programs, patient focused education, and self management protocols. This journal is indexed on PubMed Central, MedLine and CAS. The manuscript management system is completely online and includes a very quick and fair peer-review system, which is all easy to use. Visit http://www.dovepress.com/testimonials.php to read real quotes from published authors. 